University of Nebraska - Lincoln

DigitalCommons@University of Nebraska - Lincoln

May 2005

\title{
"You would if you loved me": Toward an improved conceptual and etiological understanding of nonphysical male sexual coercion
}

Sarah A. DeGue

University of Nebraska-Lincoln, sdegue@yahoo.com

David DiLillo

University of Nebraska-Lincoln, ddilillo@unl.edu

Follow this and additional works at: https://digitalcommons.unl.edu/psychfacpub

Part of the Psychiatry and Psychology Commons

DeGue, Sarah A. and DiLillo, David, "'You would if you loved me": Toward an improved conceptual and etiological understanding of nonphysical male sexual coercion" (2005). Faculty Publications, Department of Psychology. 112.

https://digitalcommons.unl.edu/psychfacpub/112

This Article is brought to you for free and open access by the Psychology, Department of at DigitalCommons@University of Nebraska - Lincoln. It has been accepted for inclusion in Faculty Publications, Department of Psychology by an authorized administrator of DigitalCommons@University of Nebraska - Lincoln. 


\title{
"You would if you loved me": Toward an improved conceptual and etiological understanding of nonphysical male sexual coercion
}

\author{
Sarah DeGue and David DiLillo \\ University of Nebraska-Lincoln
}

Submitted February 2003; revised July 2003; accepted September 2004; available online November 2004.

\begin{abstract}
This paper reviews current research regarding the prevalence and possible etiological factors associated with male sexual coercion, defined here as a class of inappropriate male behaviors in which nonphysical tactics (e.g., verbal pressure, lying, deceit, and continual arguments) are utilized to obtain sexual contact with an unwilling adult female. This form of sexual misconduct is contrasted with sexual aggression (i.e., forcible rape), in which the threat or use of physical force is utilized to gain sexual contact. A conceptual framework for understanding and examining sexual coercion within the broader context of male sexual misconduct is offered. This model consists of two primary dimensions: (1) types of sexual contact and (2) tactics for obtaining sexual contact, which intersect to form quadrants representing distinct categories of sexual misconduct. The broader sexual misconduct literature is utilized to shed light on possible predictors and etiological factors associated specifically with sexual coercion. These factors fall into four categories: (1) attitudinal or belief systems, (2) behavioral tendencies, (3) personality characteristics, and (4) childhood abuse experiences. Literature in each of these areas is reviewed and discussed. Finally, methodological and conceptual considerations for sexual misconduct research are presented.
\end{abstract}

Keywords: Sexual coercion, Sexual misconduct, Sexual aggression, Verbal coercion, Date rape, Sexual assault

Contents

1. Improving conceptual clarity. . . . . . . . . . . . . . . . . . 514

1.1. The problem of nonphysical sexual coercion . . . . . . . . . . . 517

1.2. Predicting sexual coercion: exploring potential etiological factors . . . . . . . . 518

2. Attitudinal and belief systems . . . . . . . . . . . . . . . . . . . 518

3. Bchavioral tendencies . . . . . . . . . . . . . . . . . . . . . 520

4. Personality factors . . . . . . . . . . . . . . . . . . . . . . 522

$4.1 . \quad$ Empathy. . . . . . . . . . . . . . . . . . . . . . 522

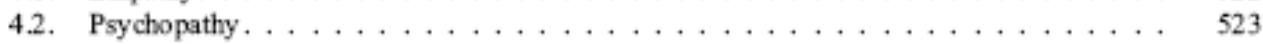

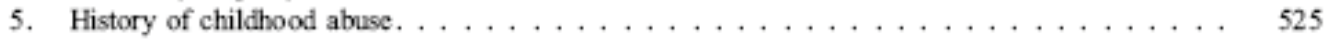

5.1. Summary of etiological factors . . . . . . . . . . . . . . . . . . 526

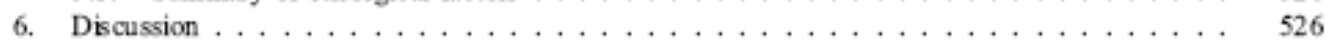

6.1. Methodological issues. . . . . . . . . . . . . . . . . . . 526

6.2. Conceptual issues . . . . . . . . . . . . . . . . . . . . . 528

6.3. Treatment implications . . . . . . . . . . . . . . . . . . . 528

References. . . . . . . . . . . . . . . . . . . . . . . . . . . 529 
The primary objective of this article is to improve current conceptual and etiological understanding of male sexual coercion. Sexual coercion, as defined here, refers to a class of inappropriate male behaviors in which nonphysical tactics (e.g., verbal pressure, lying, deceit, and continual arguments) are utilized to obtain sexual contact with an unwilling adult female. Although this definition of sexual coercion is consistent with that used by several researchers (e.g., Abbey et al., 2001, Calhoun et al., 1997, Lisak \& Ivan, 1995, Koss \& Dinero, 1988 and Koss et al., 1985), it is important to note that there has been considerable inconsistency in the literature regarding the labels and definitions used to describe the various forms of male sexual misconduct. For example, terms such as "sexual aggression" and "sexual coercion" have often been used interchangeably in reference to both physical and nonphysical tactics for obtaining sexual contact with an unwilling adult. Several other terms have also represented each of these ideas at times (e.g., rape, sexual assault, verbal coercion, physical coercion, sexual abuse, date or acquaintance rape, sexual violence). The continued use of varied terminology and ill-defined or overlapping categories of behavior presents a challenge when seeking to understand and synthesize this rather extensive area of literature (see, for example, the well-publicized debate regarding Koss, Gidycz, and Wisniewski's 1987 study of rape among college women, including criticisms by Gilbert, 1993 and Roiphe, 1993 and responses by Koss, 1992a and Koss, 1992b and Koss and Cook, 1998). Thus, before examining the etiological processes that may contribute to male sexual coercion, it is important to address some important conceptual issues related to this area of research.

\section{Improving conceptual clarity}

Despite widespread acknowledgment of the need for definitional clarity (e.g., Koss, 1992b), the persistent terminological inconsistencies within the sexual misconduct literature make comparisons across studies difficult. This is especially true for acts of sexual coercion, which, in contrast to forcible rape, do not as often constitute a legally recognized category of sexual misconduct. To help clarify the notion of sexual coercion, we propose the conceptual model depicted in Fig. 1.This

model places sexually coercive acts within the broader context of male sexual mis- 
conduct involving a nonconsenting partner. The first dimension of the model, located along the $x$-axis, represents various types of sexual contact that may occur between individuals. These range from relatively low-level sexual activities, such as fondling, at one end of the spectrum, to more intense and invasive acts, such as sexual intercourse, at the other. The second dimension, represented along the $y$ axis, reflects the specific tactics employed by perpetrators to obtain sexual contact with an unwilling participant. Mildly coercive verbal behaviors are at one end of this continuum, while more extreme tactics involving brute physical force occupy the other. A range of behaviors can be located between the endpoints of each dimension. For example, behaviors such as forced undressing, genital fondling, and oral penetration would fall between the endpoints on the type of sexual contact continuum, whereas activities such as bribery, threats of harm, and low-level physical force would fall along the tactics continuum.

In addition to representing graduated levels of behavior, the two dimensions of the model intersect to form quadrants representing discrete categories of sexual misconduct. Sexually aggressive behaviors, or those involving the use of physical force, are represented by Quadrants 1 and 2, while sexually coercive acts that in-

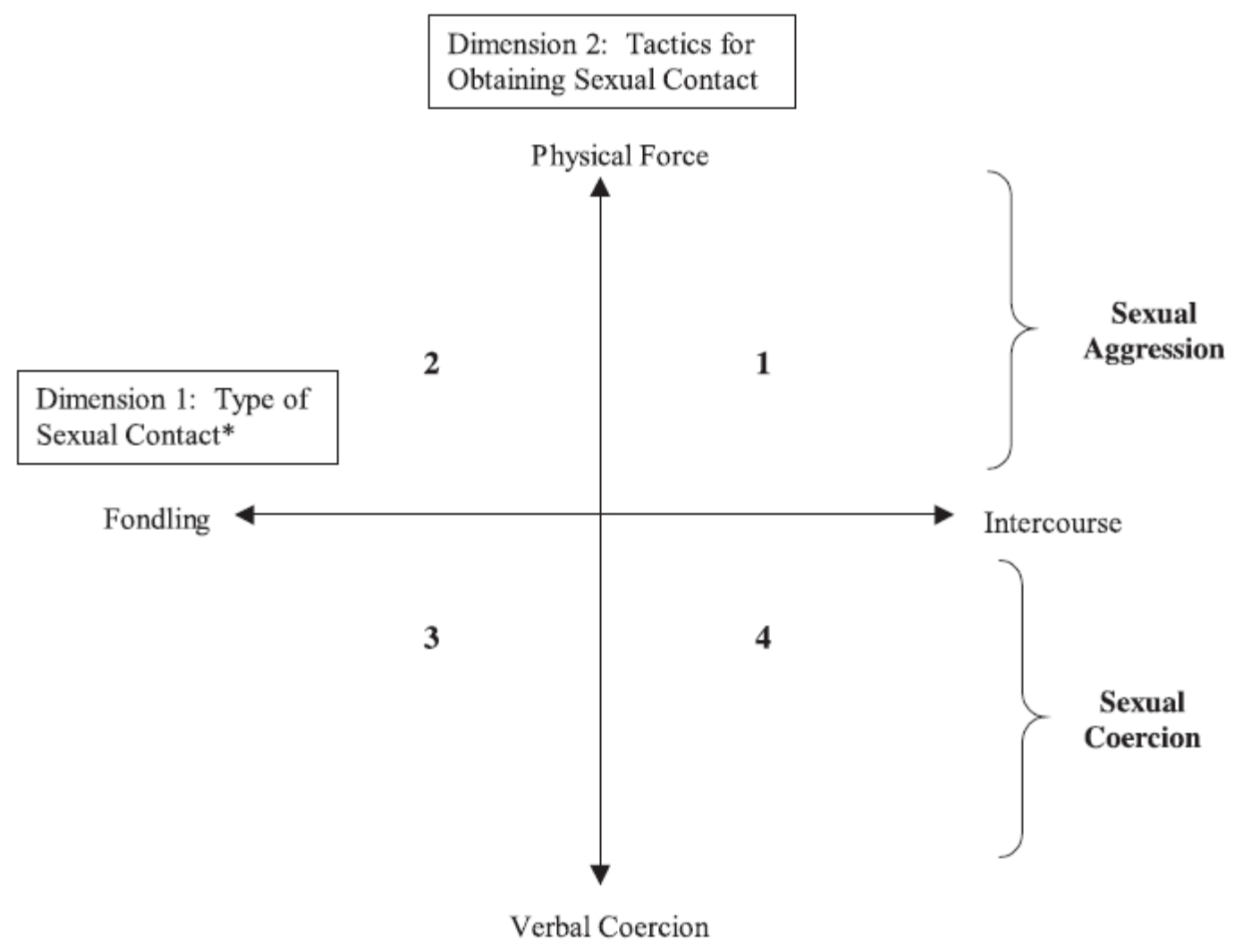

Fig. 1. A definitional model of sexual misconduct. *Note $=$ all sexual contact is assumed to be unwanted. Consent is not given or is coerced. 
volve only nonphysical tactics are contained in Quadrants 3 and 4. A brief description of each quadrant follows.

Quadrant 1 represents the most severe forms of male sexual misconduct. These behaviors include the use of physical force or threats of force to gain sexual intercourse or other penetration with a nonconsenting adult, as well as unwanted intercourse with a female that is too intoxicated to consent or physically resist. This quadrant encompasses what lay individuals may typically think of as "rape", as well as what many legal jurisdictions use to define forcible rape or serious sexual assault (Barnett, Miller-Perrin, \& Perrin, 1997).

Quadrant 2 is defined by sexual behaviors in which physical force or threats of force are used to obtain sexual contact with an unwilling partner. However, in this quadrant, sexual contact is limited to fondling or other sexual acts short of sexual intercourse or penetration (i.e., kissing or other oral contact). Behavior in this quadrant may commonly be referred to as "forced fondling" or "sexual assault". As in Quadrant 1, this category includes unwanted sexual contact with a female that is too intoxicated to physically resist. In many jurisdictions, Quadrant 2 behaviors would meet some legal standard for a sexual offense (e.g., Third Degree Sexual Assault).

Quadrant 3 includes the use of verbal coercion or manipulation (e.g., lies, guilt, false promises, continual arguments, or threats to end the relationship) to obtain sexual contact without voluntary, expressed consent. In addition, the intentional use of drugs or alcohol to impair the victim's judgment and/or resistance to sexual advances (while not rendering her unconscious or incapacitated) is included here. As with Quadrant 2, sexual contact here is limited to fondling or other less severe sexual acts and does not include acts culminating in penetration. Although clearly inappropriate, the lower level of sexual contact, less overtly aggressive tactics, and relative absence of legal prohibitions pertaining to these behaviors, suggest that Quadrant 3 behaviors may sometimes be perceived as a nuisance or minor offense, rather than a highly problematic form of sexual offending. However, other acts in this quadrant, such as pressuring an individual to undress or participate in genital fondling, are more serious in nature.

The final category, Quadrant 4, encompasses acts of genital penetration obtained through the use of nonphysical coercion or verbal manipulation, as well as intentional intoxication to impair a victim's judgment. Because these interactions sometimes involve verbalized (although coerced) consent or a lack of expressed nonconsent (e.g., neither consenting nor verbally objecting), Quadrant 2 behaviors are less often prosecuted. Despite the lack of legal prosecution, researchers have begun to address the prevalence and seriousness of this form of sexual misconduct.

It should be noted that the model presented here overlaps significantly with the categories of sexual misconduct suggested by Koss et al. in the literature (e.g., Koss \& Gidycz, 1985, Koss et al., 1985 and Koss et al., 1987) and utilized by several other researchers (e.g., Abbey et al., 2001). However, some of the specific categories used by Koss (sexual contact, sexual abuse, sexual coercion, sexual assault, attempted rape, rape) do not directly correspond to the quadrants described above. 


\subsection{The problem of nonphysical sexual coercion}

Although sexually coercive acts involving nonphysical tactics are, by definition, less severe than physically aggressive offenses, evidence indicates that this type of victimization is a widespread societal problem that poses a potential threat to women's well-being. Researchers have consistently reported rates of sexual coercion that are similar to or higher than rates of sexual aggression (e.g., forcible rape). In an early study of sexual coercion, $22.4 \%$ of college males reported utilizing extreme verbal pressure to obtain sexual intercourse with an unwilling female (Koss et al., 1985). Further research has reported even higher rates of coercion among college males. For instance, 37\% (Byers \& Eno, 1991) to 69\% (Mosher \& Anderson, 1986) of college men have admitted to using tactics of verbal manipulation to obtain sex, and as many as $75 \%$ admitted to "using drugs or alcohol...in order to have sex with a date" (Mosher \& Anderson, p. 83). Although some researchers have reported lower rates of sexual coercion [e.g., Abbey et al., 2001 (10\%); Koss \& Dinero, 1988 (7.2\%)], the rates reported were still similar to or higher than those for sexual aggression. In addition, studies reporting lower prevalence rates have often provided data for a narrower range of sexually coercive behavior that includes only higher level coerced sexual contact (i.e., Quadrant 4), while combining lower level contact obtained by physical and nonphysical methods (i.e., Quadrants 2 and 3) into one category (often called sexual contact; e.g., Koss \& Dinero; Koss et al., 1987). Sexual coercion is not limited to college campuses, though available evidence suggests that prevalence rates may be slightly lower in community samples. Calhoun et al. (1997) reported that $22 \%$ of men in their community sample had engaged in intercourse subsequent to the use of "menacing verbal pressure and/or continual arguments," with $86 \%$ of the coercers admitting to more than one incident (p. 398). Similarly, using a Canadian community sample, Senn, Desmarias, Verberg, and Wood (2000) found that 27\% of males reported using some form of sexual coercion or aggression. Finally, a study from the victims' perspective found that more than half $(50.5 \%)$ of a high-risk sample, defined as "single women, 20-35, who drink at bars and parties", had experienced sexual coercion on at least one occasion (Testa \& Dermen, 1999, p. 551).Thus, despite some inconsistencies based on definition and sample, the rates of sexually coercive behaviors reported across studies point to these behaviors as a serious problem for women.

Studies have revealed a range of lasting negative correlates associated with overt sexual aggression. These outcomes include increased anxiety and other psychiatric symptoms, sexual dysfunction, and poorer social adjustment among victims (see Harney \& Muehlenhard, 1991 for a review). In contrast to sexual aggression, few researchers have begun to explore long-term correlates specifically associated with nonphysical sexual coercion. In one of the only studies to examine this issue, Zweig, Barber, and Eccles (1997) compared psychosocial characteristics associated with specific types of sexual misconduct. Using a sample of 872 college females, the authors found that victims of sexual coercion (defined as verbal pressuring) had lower self-esteem and were more socially isolative than nonvictims. Victims of sexual coercion also reported more depressed mood and social anxiety than did nonvictims or victims of sexual aggression (Zweig et al., 1997). Of course, these difficulties may have predated the coercive encounters. 
Regardless of whether sexual coercion produces lasting negative effects, such acts, by their very nature, constitute a violation of an individual's right to make unfettered decisions about the circumstances in which she or he engages in sexual activity. Further, even in the absence of long-term harm, many victims may feel exploited by the physical and emotional violations that are an inherent part of such experiences. Victims may also experience personal distress in the form of heightened feelings of vulnerability, confusion, betrayal, and a sense of self-blame or shame regarding a perceived inability to resist or protect themselves from coercive manipulation. Moreover, the increased risk of sexually transmitted diseases including HIV and unplanned pregnancy as a result of coerced intercourse is a clear threat to women's health and well-being.

\subsection{Predicting sexual coercion: exploring potential etiological factors}

As noted, sexual misconduct exists on a continuum, with tactics ranging from mild nonphysical coercion to severe physical aggression. Some authors have suggested that sexual coercion represents a milder form of sexual aggression (Testa \& Dermen, 1999), a notion implying that "lower level" coercive acts may share a similar set of etiological factors with more overtly aggressive sex offenses. Consistent with the idea of a continuum of sexual misconduct, many researchers have, for the purposes of analyses, chosen to combine sexually coercive and aggressive acts into a single category of sexual offending, rather than examining unique predictors of coercive versus aggressive tactics (e.g., Aberle \& Littlefield, 2001, Senn et al., 2000, Bernat et al., 1999, Bernat et al., 1998, Lisak, 1994 and Rapaport \& Burkhart, 1984). Other researchers have separated different forms of sexual misconduct in a portion of analyses, but have not specifically examined factors that differentiate sexual coercion and aggression or that characterize coercive men specifically. Therefore, despite the prevalence of sexual coercion and the possibility of associated short-term distress, relatively little has been done to understand the unique etiological factors associated with this particular form of sexual misconduct.

Because little research has specifically addressed sexual coercion, it is useful to draw on the broader sexual aggression literature when attempting to identify relevant etiological factors. As a whole, this literature points to a multifactor conceptualization of coercion determinants, which is consistent with the recommendations of others who have stressed the need to consider the convergence of many variables in explaining sexual offending (Koss, 2000 and Nagayama Hall \& Hirshman, 1991). Here, the factors most clearly associated with male sexual coercion are placed into four categories, including: (1) attitudinal or belief systems, (2) behavioral tendencies, (3) personality characteristics, and (4) childhood abuse experiences. Research regarding each of these predictor groups and their potential relationships with sexual coercion is discussed below.

\section{Attitudinal and belief systems}

One common focus of research has been in the domain of attitudes and beliefs that may contribute to various forms of sexual misconduct. In the 1970s and 1980s, rape researchers began alluding to the concept of "rape myths" as an etiological factor in the development of sex offending. Burt (1980) defined rape myths as "prejudi- 
cial, stereotyped, or false beliefs about rape, rape victims, and rapists... [which create] a climate hostile to rape victims" (p. 217). This line of work revealed that these belief systems not only result in negative reactions to victims and tolerant attitudes towards offenders, but that they might also serve as risk factors for engaging in offending behavior. In addition, Burt pointed to the pervasive nature of these beliefs in the US and their origination in "sex role stereotyping and the psychological availability of violence" (p. 229). A set of scales developed by Burt (1980; Own Sex Role Satisfaction, Sex Role Stereotypes, Adversarial Sexual Beliefs, Sexual Conservatism, and Acceptance of Interpersonal Violence) have been used extensively, initially in studies of rape behavior and later in research on sexual coercion. Studies using these scales have found reliable relationships between rape-related attitudes and cognitions, and sexual behavior. For instance, Byers and Eno (1991) found correlations ranging from 0.21 to 0.44 between three of Burt's scales and measures of participants' sexually coercive or aggressive behavior. Of these attitudinal measures, the strongest correlations were found between Rape Myth Acceptance (RMA) and coercion $(r=0.42)$, and between Acceptance of Interpersonal Violence (AIV) and the use of physical force $(r=$ 0.44). In fact, of all the attitudinal and non-attitudinal predictive measures utilized by Byers and Eno, the RMA and AIV had the strongest correlations overall with coercive and aggressive sexual behavior, respectively. Other researchers using college samples have also reported associations between the Burt scales and sexual misconduct, when considered either as a continuous variable (e.g., Hersh \& Gray-Little, 1998) or a categorical variable comparing coercive, aggressive, and nonoffending men (e.g., Koss \& Dinero, 1988 and Muehlenhard \& Falcon, 1990).

The attitudes and beliefs associated with sexual coercion and aggression extend beyond the rape myths as defined by Burt (1980). Other researchers have found that angry and distrustful feelings towards women may also be a factor in sexual aggression, though the results are mixed regarding sexual coercion. For example, the Hostility Towards Women (HTW) Scale, introduced by Check, Malamuth, Elias, and Barton (1985), taps such attitudes (e.g., "Many times a woman appears to care, but just wants to use you"). Byers and Eno (1991) reported significant relationships between HTW and sexual coercion and aggression ( $r=0.30$ and 0.22 , respectively) in college males. Further, Malamuth, Heavey, and Linz (1993) reported that HTW was one of four significant contributors to a model predicting a continuum of sexual misconduct. Results from a rural sample indicated that HTW predicted sexual aggression, though it was unrelated to sexual coercion (Calhoun et al., 1997). The HTW also entered a multifactor model of sexual misconduct developed by Koss and Dinero (1988) as a predictor of both coercive and aggressive behaviors. Lisak and Roth (1988) assessed underlying anger motivations for sexual misconduct and found that angry feelings towards women differentiated between men who engage in sexual misconduct and those who do not, but did not distinguish between types of offenders (e.g., aggressive, coercive, and non-offenders).

Since these first measures were developed, many researchers have found support for the role of additional attitudes and beliefs in the acceptance and perpetration of sexual misconduct. For instance, Malamuth, Check, and Briere (1986) found that acceptance of male aggression and dominance in relationships with 
women were related to increased physical arousal to audiotaped portrayals of forced sexual contact in a college sample. Utilizing the Attitudes Towards Women Scale (Spence, Helmreich, \& Stapp, 1973), Koss et al. (1985) measured acceptance of traditional sex-role stereotypes and found a strong correlation with sexual aggression in particular. Bumby (1996) developed the RAPE Scale to assess cognitive distortions associated with sexual aggression, and at the same time updated the Burt (1980) scales by assessing similar concepts using more current language. Although this measure was validated only with sexual aggressors (i.e., convicted rapists), Bumby (1996) found a significant relationship between the attitudes assessed by the RAPE Scale and extent of sexual offense history. Finally, a study by Tyler, Hoyt, and Whitbeck (1998), which examined predictors of sexual coercion and aggression separately, found that more permissive attitudes about sex (e.g., "I believe that sexual intercourse is acceptable on the first date") were associated with verbal sexual coercion, while acceptance of sexual aggression under certain conditions (e.g., "he spends a lot of money on her", "he is so turned on that he cannot stop") was associated with both sexually coercive and aggressive behavior.

Overall, the available evidence suggests that rape myth acceptance is an important predictive factor for both sexually coercive and aggressive behaviors, while other attitudinal and belief characteristics may be more helpful in differentiating between these offender groups. For example, sexual coercion appears to be more related to permissive or stereotypical attitudes about sex and women, whereas sexual aggression is associated with hostile and distrustful feelings towards women and acceptance of violent behavior in intimate relationships. The ability of attitudinal and belief systems to predict and distinguish between sexual coercion and aggression suggests that this is an important category of factors to consider in exploring the etiology of sexual coercion.

\section{Behavioral tendencies}

Although less prominent in the literature than cognitive variables, evidence has accumulated in support of several behavioral variables, such as delinquency, sexual promiscuity, and nonsexual aggression, as possible predictors of sexual misconduct. Malamuth, Sockloskie, Koss, and Tanaka (1991) utilized structural equation modeling to examine the factors involved in sexual and nonsexual aggression towards women. A strength of this study is that it utilized a nationally representative sample of almost 2500 male college students in the US. Malamuth et al. (1991) identified a pattern in which negative childhood experiences (e.g., physical abuse, witnessing violence) increase involvement in delinquency and lead to aggression against women through one of two paths - either by creating hostile personality features and attitudes or by increasing the likelihood of promiscuity. The authors argue that the path wherein early experiences result in delinquency, which, in turn, leads to promiscuity, is most strongly related to sexual aggression specifically, as opposed to generalized aggression. Therefore, as Malamuth et al. (1991) point out, behaviors that characterize delinquency and promiscuity are "important parts of the puzzle" (p. 678) and should be considered in any comprehensive look at sexual aggression. Although the delinquency-promiscuity link has not been studied in relation to sexual coercion, 
these factors could conceivably predict this behavior as well. In fact, other studies have provided further support for the role of sexual promiscuity in the perpetration of both sexual coercion and aggression (e.g., Abbey et al., 2001, Abbey et al., 1998 and Koss et al., 1985).

Another notable implication of the Malamuth et al. (1991) study is that sexual and nonsexual patterns of aggression may be closely related, despite their distinct predictors. If the two forms of aggression are, in fact, related, then each may serve as a reliable predictor of the other. Specifically, nonsexual or generalized aggression could be predictive of sexual misconduct. Indeed, Hersh and Gray-Little (1998) reported that the sexually coercive and aggressive college men in their study were higher in overall aggressiveness than were those men who had experienced consensual sex only. Koss and Dinero (1988) also reported that a violent aggression score derived from the Conflict Tactics Scale (Strauss, 1979) differentiating groups of offenders, including coercers and aggressors. Similarly, some authors (e.g., Brownmiller, 1975 and Groth, 1979) have argued that sexual aggression may be motivated more by hostility or power, than by sexual desire. Traditionally based in feminist theory, this argument has been supported by data suggesting that the majority of rapists are sexually active in consensual relationships (e.g., Groth, 1979). Little is known, however, about the validity of this theory when applied specifically to sexually coercive behavior. It is possible that differences in the offense type (physical aggression versus strictly verbal coercion) represent differences in motivation as well. For instance, sexual aggression may, as some have argued, be more closely tied to generalized aggression or hostility given the potential for physical harm to the victim and overtly hostile nature of the act. By contrast, the motivation for coercive behavior may more often be sexual, in that a variety of tactics are utilized with the primary goal of obtaining seemingly consensual sexual contact, with the offender perhaps minimizing the degree of the victimization. Alternatively, verbal coercion may simply be another means of exerting control and expressing hostility or aggression towards women through the use of manipulation. Because research looking specifically at sexual coercion has rarely assessed generalized aggression, this may be a behavioral factor worth exploring further.

In addition to delinquency, promiscuity, and aggression, another variable termed "rape proclivity" has surfaced as a correlate of sexual misconduct and is probably best described as a behavioral variable. Malamuth (1981) first addressed the concept of "rape proclivity" by asking a sample of men to "indicate the likelihood that they personally would rape if they could be assured of not being caught or punished" ( $p$. 140). Results from this study indicated that participants who rated themselves higher on "likelihood of raping" were more similar to convicted rapists in terms of belief in rape myths and physical arousal to rape depictions. Furthermore, those who reported being more likely to rape showed greater aggression toward females in a laboratory task. In another study, participants were classified based on their reported willingness to "force a woman to do something sexual" or "rape" on two items phrased similarly to the rape proclivity item described above (Malamuth, 1988). Results suggested that sexually aggressive men were more likely to endorse both items than were sexually coercive men. In fact, sexually coercive men endorsed these items 
only slightly more than nonoffending men. Although results are unclear regarding the utility of rape proclivity in predicting coercion, available evidence suggests rape proclivity is a potentially important predictor of sexual and perhaps nonsexual aggression towards women.

\section{Personality factors}

The possibility that sex offenders possess certain personality characteristics has been studied fairly extensively among convicted rapists. From this research, two primary personality factors have emerged as contributors to sexual aggression: empathy and psychopathy. Some researchers examining these constructs have begun to expand their work to include measures of sexually coercive behavior as well, providing some preliminary evidence of a relationship between these personality factors and nonphysical means of offending.

\subsection{Empathy}

Empathy has been defined as "a set of constructs having to do with the responses of one individual to the experiences of another" (Davis, 1996, p. 12). Definitions of empathy have varied, but usually include the abilities to adopt the perspective of another person or character, to have feelings of concern and sympathy for others, and to feel personally distressed in response to the distress of another. Davis' (1980) measure of empathy divides empathic abilities into four components: Perspective-taking, Fantasy, Empathic Concern, and Personal Distress. Other researchers have used different frameworks to describe the construct of empathy, though these same basic abilities remain the focus. For example, Marshall and Maric (1996) and Marshall et al. (1995) proposed a differentiation between the emotional and cognitive components of empathy, and suggested that different patterns of empathic deficits may be possible. In addition, other authors (e.g., Fernandez \& Marshall, 2003 and Marshall et al., 1995) have distinguished between trait empathy and victim-specific empathy, pointing to evidence that some convicted sexual offenders (i.e., rapists and child molesters) may suppress their empathic response toward their victim in offense-related situations, while demonstrating no empathic deficits under other circumstances. Furthermore, Smallbone, Wheaton, and Hourigan (2003) reported evidence from a sample of 88 incarcerated adult sexual offenders suggesting a stronger negative relationship between trait empathy and criminal versatility (multiple offense types) or generalized violent offending than between trait empathy and sexual offending. They also noted that sexual offenders in their sample were more likely to have previous convictions for nonsexual offenses than sexual offenses and that the majority $(60 \%)$ of the sexual offenders were previously convicted on nonsexual crimes. Thus, although the exact nature of the relationship between empathy and sexual offending remains unclear, the hypothesized mechanism by which empathic deficits may relate to sexual offending is fairly straightforward. Whereas men with an intact capacity for empathy may be dissuaded from coercive or aggressive sexual acts by detecting or imagining the impact of such behaviors on a potential victim, deficits in empathic abilities may represent one less barrier for perpetrators to surpass before engaging in behaviors that rise to the level of sexual misconduct. Furthermore, in the absence 
of empathy, perpetrators would lack negative reinforcement in terms of guilt or remorse that might otherwise curb their patterns of sexual misconduct.

To gauge empathic response in sexual aggressors and coercers, Lisak and Ivan (1995) utilized several measures in a sample of college males, including a questionnaire on emotional empathy, a facial affect recognition task, and a scale assessing alexithymia, the inability to identify and express verbally one's own emotional state. In this study, the combined group of sexually coercive and aggressive men reported lower emotional empathy and made more errors identifying male facial affect than did the nonaggressive men. Interestingly, coercive and aggressive men in this study did not differ from nonoffenders in their ability to identify female facial expressions, suggesting that this capability may not account for differences in relative levels of empathy between these groups. Unfortunately, analyses did not separate sexually aggressive and coercive participants. Another study by Senn et al. (2000) assessed the concept of restrictive emotionality in a primarily Caucasian community sample and found that this variable contributed significantly to a model predicting sexual misconduct. Interestingly, adolescent promiscuity and child abuse were the only other variables to enter the model, while traditional attitudinal/belief variables were not found to differentiate sexual aggressors and coercers from non-aggressors. In their study of a juvenile population, Lindsey, Carlozzi, and Eells (2001) reported that juvenile delinquents who had been convicted of sexual offenses scored significantly lower than non-sexual offending delinquent youth on the Empathic Concern subscale of the Interpersonal Reactivity Index (IRI; Davis, 1980). Furthermore, juvenile sex offenders and non-sex-offending delinquents scored higher than nondelinquent youth on the Personal Distress subscale of the IRI, which assesses a person's anxiety level when observing the negative experiences of another. The authors suggest that this focus on one's emotional reaction may distract these individuals from concern for the victim or distressed other. Overall, this research suggests a possible relationship between empathic deficits and sexual aggression. Given the presence of child molesters in this sample (offenders that often employ tactics of nonphysical manipulation), it is possible that these findings might generalize to sexual coercers of adult women as well. In addition, further study may reveal patterns of association between aspects of the empathy construct and specific forms of sexual misconduct (i.e., coercion versus aggression).

\subsection{Psychopathy}

The most widely accepted and empirically tested definition of psychopathy is based on the Psychopathy Checklist (PCL; Hare, 1991), a behavioral rating scale utilizing clinical interviews and record reviews. Hare's definition of psychopathy consists of two dimensions. Factor 1 includes "the interpersonal/affective features of psychopathy, such as egocentricity, manipulativeness, callousness, and lack of remorse", while Factor 2 focuses on the social deviance aspects of psychopathy, such as "an impulsive, antisocial, and unstable lifestyle" (Hare, 1998, p. 193). Each dimension of psychopathy has been found to correlate independently with a variety of behaviors and characteristics. Regarding sexual misconduct, the construct of psychopathy seems to occur at relatively high rates among incarcerated 
rapists, with these offenders being the "most likely to recidivate early and often" (Hare, p. 201). Though the presence of psychopathy is not necessary for the commission of sexual offenses, it seems to increase the likelihood that a potential offender will carry out such behaviors. This may be due to the combination of specific traits, each of which make it more likely that a person will break the law (i.e., contempt for rules and authority, criminal history, need for stimulation), cause harm to another person (i.e., lack of guilt, empathy, or responsibility for one's actions), use others for personal gain (i.e., manipulativeness, pathological lying, narcissism), or act without considering consequences (i.e., impulsivity, irresponsibility, poor behavioral controls). Certainly, any of these behaviors could be theoretically related to acts of sexual aggression. Although less evidence exists in regards to psychopathy among sexually coercive men, it is possible that the presence of these traits could provide some predictive power in this realm as well. For instance, sexually coercive behavior often involves the use of the victim for personal gain without acknowledgement of or respect for her wishes (i.e., manipulativeness) and could be rationalized by perpetrators as an inability to control one's sexual advances (i.e., poor behavioral controls).

Hersh and Gray-Little (1998) measured several traits associated with the construct of psychopathy, including manipulativeness, impulsivity, sensation-seeking, and empathy. These authors defined groups of sexual misconduct by the level of unwanted contact (e.g., fondling, intercourse, etc.) rather than the tactics utilized (e.g., nonphysical, physical, etc.), thus the categories of offenders analyzed include both sexually coercive and aggressive men. Data on the tactics used within each group were not reported. In this study, Hersh and Gray-Little found that the most sexually inappropriate group in their sample (defined as those who engaged in unwanted intercourse) were more manipulative and sensation-seeking than the men who engaged in lower level contact. Also, men who engaged in any coercive or aggressive behavior were more manipulative and impulsive, and less empathic, than those reporting only consensual relationships. Using a male college sample, Rapaport and Burkhart (1984) found that college males who endorsed higher level coercive and aggressive acts were less likely to act in a personally and socially responsible manner or to have internalized and acted on pro-social values. Kosson and Kelly (1997) also examined the relationship between psychopathy and sexual misconduct (including several categories of sexual coercive and aggressive acts) by administering a version of the SES (Koss et al., 1987) to a sample of college men $(\mathrm{N}=378)$. The results suggested that measures assessing both dimensions of psychopathy (i.e., Factors 1 and 2) were uniquely associated with specific types of coercive or aggressive behavior. More specifically, certain forms of sexual coercion (i.e., the use of authority or argument, manipulative intoxication) were associated with narcissistic personality features and poor socialization, whereas sexual aggression (i.e., the use of force or threats) was associated most strongly with Factor 1 of the PCL, which assesses the "callous, remorseless manipulation of others" (p. 241). In addition, the authors reported that an interaction between socialization (assessed by the CPI subscale) and PCL Factor 1 contributed to the prediction of more forms of sexual misconduct than any other factor or interaction assessed. 
In light of this literature on sexual misconduct and personality traits, the constructs of empathy and psychopathy seem promising areas for further empirical attention. Evidence suggests that empathic deficits may increase risk for sexual misconduct by diminishing potential deterrents to perpetration, such as feelings of empathy, guilt, and remorse. Similarly, the presence of psychopathic traits may increase the likelihood of sexual aggression or coercion by making it easier for individuals to participate in antisocial behavior. Thus, these constructs will likely prove valuable in further research examining the predictors of sexual coercion in isolation.

\section{History of childhood abuse}

The prevalence, characteristics, and negative developmental impact of childhood maltreatment (i.e., physical, sexual, and emotional abuse, neglect, exposure to domestic violence) have been studied extensively in recent years. Included in this literature is a body of work regarding the "cycle of abuse" theory. Specifically, researchers have considered whether the presence of childhood abuse increases the risk of victimizing others as an adult. Although much of this work has focused on adult perpetrators of child sexual abuse, some studies have found a relationship between child maltreatment experiences and adult aggression towards women. For instance, Dhawan and Marshall (1996) reported that $62 \%$ of the convicted rapists versus $20 \%$ of the nonsexual offenders in their study were classified as having been sexually abused as children, although the sample size used was relatively small. Koss and Dinero (1988) developed a multifactor model of sexual misconduct using discriminant function analysis. The model, which included a variable assessing family violence, was able to discriminate between various forms of sexual misconduct, including sexual coercion and aggression. Unfortunately, the analyses did not provide data on the types of abuse experienced or the specific relationship between these experiences and the different forms of sexual misconduct (e.g., coercion versus aggression). Widom, 1989 and Widom, 2000 reported findings related to generalized violence in adulthood. Specifically, this large-scale, longitudinal study looked at multiple types of child maltreatment and adult arrest rates for violent offenses. Results suggested that physical abuse was most strongly related to later nonsexual, violent offending, though neglect and sexual abuse also had demonstrated relationships to violence. Although not speaking to sexual violence specifically, Widom (2000) suggests that more focus be devoted to identifying the individual effects of various types of abuse, as different coping strategies or mediating variables may be relevant for each. Consistent with this suggestion, Simons, Wurtele, and Heil (2002) found that convicted sex offenders who reported child physical abuse experiences were more likely to have raped adult women, whereas offenders with child sexual abuse histories were more likely to have child victims. This suggests a need to assess and report more detail regarding childhood abuse types than has been done in past studies (e.g., Koss \& Dinero, 1988). Finally, using a large, representative sample of college men, Malamuth et al. (1991) developed a model illustrating the characteristics of sexual and nonsexual aggressors against women. As noted previously, this study identified two pathways to sexual and nonsexual violence towards women. Interestingly, both pathways originated with hostile home environments, specifically including child abuse and exposure to parental violence. Thus, Malamuth et 
al. identified the presence of child maltreatment as an important distal factor in aggression against women.

Despite the body of evidence relating early victimization history to adult sexual and nonsexual violence, childhood maltreatment has rarely been examined in its relationship to sexual coercion specifically. In one recent study including sexual coercers, Senn et al. (2000) utilized items assessing early experiences of physical and sexual abuse in a community sample. They reported that a history of victimization significantly increased the chances that a participant would report engaging in some form of sexual misconduct, although analyses were not conducted for coercive and aggressive behaviors separately. Thus, taken in combination, available evidence from the coercion and aggression literature suggests a potential link between victimization history and the perpetration of sexual coercion that may be worth considering in more depth.

\subsection{Summary of etiological factors}

As suggested here, the combined literature on coercive and aggressive sexual misconduct brings to light four classes of predictors that may be important to consider in future work focused specifically on sexual coercion. These groups include: attitudinal or belief-related factors, behavioral tendencies, personality factors, and childhood abuse experiences. Not all of the factors within each category have been examined specifically in relation to sexual coercion. In fact, few studies have examined these factors for sexual coercion in isolation, but rather have looked at sexual aggressors alone or combined groups of sexual coercers and aggressors in analyses. Among attitudinal/belief factors, some measures with strong relationships to sexual aggression may be less consistently related to sexual coercion (e.g., Hostility Toward Women), while others appear to be uniquely associated with either coercion (e.g., Rape Myth Acceptance) or aggression (e.g., Acceptance of Interpersonal Violence). Many of the behavioral factors discussed, which show consistent links to sexual aggression alone or combined groups of coercers and aggressors, have not been studied in relation to sexual coercion specifically. However, some research findings do suggest a positive association between generalized aggression and coercive sexual behavior. More data are available regarding the role of personality factors in predicting male sexual coercion, with several studies suggesting relationships between each of two personality variables, empathic deficits and psychopathy, and sexually coercive behavior. Within the spectrum of psychopathic traits, narcissism and poor socialization have been linked to sexual coercion, while sexual aggression may be more closely tied to a tendency toward callous manipulation of others. Finally, although exposure to childhood victimization has been studied fairly extensively in relation to adult perpetration of sexual and nonsexual violence against women, further research is needed to examine child abuse as a determinant of sexually coercive behavior in adulthood.

\section{Discussion}

\subsection{Methodological issues}

A clear understanding of the sexual misconduct literature necessitates mention of several methodological issues common to this area of research. First, it is notable 
that research in the area tends to rely on retrospective self-report measures of sexual behavior provided by either victims or perpetrators. Regardless of whether the prevalence rates of sexual misconduct are obtained from the victim or offender perspective, the results of such measures depend on the accuracy of memories and participants' willingness to disclose sensitive information in a truthful manner. Koss (1993) pointed to two types of non-reporting that should be addressed by researchers: purposive (withholding relevant experiences) and unintentional (lack of recall). Specific biases in prevalence data may also result from the decision to use self-reports of sexual misconduct from either the victim (female) or perpetrator (male) standpoint, each of which may be associated with different reporting biases. Unfortunately, few alternatives to retrospective self-report measures are available, except in rare instances in which police documentation or other records can be used to confirm sexual misconduct. However, due to the underreporting of these types of offenses, even these methods may not provide a representative picture of sexual misconduct in general. Furthermore, because sexual coercion alone is very rarely prosecuted, sampling known offenders regarding their behavior is not feasible. Thus, self-report measures continue to be the most effective means of assessment available to researchers in this area. In order to maximize the benefits and minimize the weaknesses of this method, the quality of self-report measures utilized should be considered in light of the sample used and types of reporting biases expected.

One specific tool for assessing sexual coercion deserves special mention. The Sexual Experiences Survey (SES), developed by Koss and Oros (1982) and revised by Koss et al. (1987), has been utilized extensively in the sexual misconduct literature to assess a history of sexually coercive and aggressive behavior or victimization. Although this instrument has many strengths, including strong psychometric properties and ease of administration (Koss \& Gidycz, 1985), there may be inherent limitations to such a heavy reliance on any measurement tool, especially when assessing complex constructs such as sexual coercion and aggression. While the SES includes well-conceived items intended to assess a range of coercive and aggressive behaviors, the situations and activities described do not (and probably cannot) provide a complete assessment of all possible sexual misconduct scenarios. Thus, the types of behavior excluded may result in gaps in the literature that need to be addressed through other means. For example, Alksnis, Desmarias, Senn, and Hunter (2000) concluded that aggregating items dealing with the threat and actual use of physical force resulted in an underestimate of abuse rates detected by the SES. These results underscore the fact that differential outcomes can be obtained merely as a function of the number and type of screening questions used. Several researchers have utilized modified versions of the SES or have developed their own measures of sexual misconduct (e.g., Forbes \& Adams-Curtis, 2001, Tyler et al., 1998, Calhoun et al., 1997 and Lisak \& Roth, 1988). For example, the Sexual Experiences Questionnaire (Lisak \& Roth, 1988) includes changes to the phrasing of items to correct those thought to be confusing or outdated. More work will be necessary to ensure a complete picture of sexual coercion.

Although a variety of samples have been utilized in sexual aggression research (e.g., convicted rapists, college students, community samples), most studies including analyses on sexual coercion specifically have been conducted with college 
populations. This trend is probably due to the ease of obtaining these participants and the perception that this group is at an especially high risk for engaging in this behavior or being victimized (Forbes \& Adams-Curtis, 2001). Of course, college student samples may lack a diversity of ethnicity, age, and socioeconomic status that would aid in generalizing findings from these studies. While some researchers have assessed sexual coercion in community populations (e.g., Calhoun et al., 1997), even these samples have tended toward ethnic homogeneity. Clearly, an increased use of community samples and the extension of sexual coercion research to diverse racial and ethnic groups is a critical direction for future research.

\subsection{Conceptual issues}

With the exception of a few studies noted here, researchers have tended to "lump together" different types of male sexual misconduct, with inadequate regard to the nature of the activities involved or the tactics used by perpetrators against victims. Implicit in this practice is the assumption that sexually coercive and sexually aggressive behaviors fall within the same class of sexual misconduct and share similar etiological processes. Such a view would place coercion and aggression on a continuum of escalation, with sexual coercion perhaps serving as a stepping stone to more serious aggressive offending. Individual perpetrators would be understood as capable of committing both coercive and aggressive acts, with coercive acts perhaps representing a point of entry for a gradually escalating pattern of sexual misconduct (analogous to the view of marijuana as a "gateway drug" for the subsequent use of harder substances). According to this conceptualization, a similar set of predisposing characteristics might explain each type of misconduct, with the primary distinction being the number or degree of risk factors present. Although it is possible that coercive and aggressive acts differ primarily in terms of degree of severity, a model suggesting more qualitative differences could also be proposed. In such a model, sexually coercive and aggressive acts would be viewed as fundamentally different, likely to be performed by different types of individuals who can be differentiated by characteristics specific to one form of misconduct or the other. According to this conceptualization, involvement in one type of sexual misconduct, such as coercion, would be unlikely to lead to the perpetration of more overtly aggressive offenses. Despite the plausibility of each of these conceptualizations, very little is currently known about the nature of the relationship between sexually coercive acts and those involving more blatant physical aggression. Future research directly comparing characteristics of these two groups would be beneficial to this area of the literature and would provide an improved understanding of sexual coercion.

\subsection{Treatment implications}

A better understanding of the associations between coercive and aggressive acts could point the way toward interventions tailored to one or the other group. Thus, if evidence surfaces that sexual coercion is indeed a gateway to more overtly aggressive acts, such information could prove valuable in the development of prevention efforts. Rape prevention programs and crisis intervention centers on col- 
lege campuses and in the community are increasingly common (e.g., Berkowitz, 2001). However, reviews of program effectiveness have been mixed and several authors have cited the insufficiency of current efforts toward prevention (e.g., Davis \& Liddell, 2002, Forman \& Wadsworth, 1985, Gidycz et al., 2001 and Schewe \& O'Donohue, 1996). More specific information concerning the relationship between sexual coercion and aggression, as well as the characteristics of potential offenders, could help identify targets for and increase the effectiveness of prevention efforts. If, for example, evidence suggests that sexual aggressors initially engage in lower level sexual misconduct (i.e., sexual coercion), identifying these individuals at this earlier stage may prove helpful for prevention and intervention. Conversely, if further data indicate that potential rapists and coercers are different types of people, alternative intervention strategies would be warranted for each. Several researchers have proposed and studied typologies of adult and juvenile sexual offenders (e.g., Hunter et al., 2003, Knight et al., 1989, Knight \& Prentky, 1990 and Worling, 2001). However, these models have focused mostly on classifying rapists and pedophiles, with little attention given to the possibility of a sexually coercive subtype. Consideration of this group would further research in the field of sexual misconduct, while also opening an additional avenue for preventive interventions.

Related to the need to distinguish between coercive and aggressive offending is the issue, noted earlier, of significant inconsistencies in the labels and definitions utilized within the sexual misconduct literature. If research is to progress most effectively, a move toward consistency in terms and definitions will be important. Toward this end, we have provided a two-dimensional model that uses behaviorally specific descriptors to place sexually coercive and aggressive acts within the broader context of male sexual misconduct. Of course, it is rarely possible for a single framework to account for all perspectives, theories, and fluctuating viewpoints that accompany complex, socially derived concepts such as sexual misconduct. For example, other models have also been offered in the literature, which differ in structure and definition from that presented here. As noted, however, despite some dissimilarities, some of these definitional systems (e.g., Koss \& Gidycz, 1985 and Koss et al., 1985) are generally compatible with the model we have proposed. Perhaps this signals some movement toward consistency in the literature, as the adoption of common conceptual models will be important to the continued growth and integration of knowledge in this area.

\section{References}

Abbey et AL., 1998 A. Abbey, P. McAuslan and L.T. Ross, Sexual assault perpetration by college men: The role of alcohol, misperception of sexual intent, and sexual beliefs and experiences, Journal of Social and Clinical Psychology 17 (1998), pp. 167-195.

Abbey et Al., 2001 A. Abbey, P. McAuslan, T. Zawacki, A.M. Clinton and P.O. Buck, Attitudinal, experiential, and situational predictors of sexual assault perpetration, Journal of Interpersonal Violence 16 (2001) (8), pp. 784-807.

Aberle \& Littlefield, 2001 C. Aberle and R. Littlefield, Family functioning and sexual aggression in a sample of college men, Journal of Interpersonal Violence 16 (2001) (6), pp. 565-579. 
Alksnis et AL., 2000 C. Alksnis, S. Desmarais, C. Senn and N. Hunter, Methodological concerns regarding estimates of physical violence in sexual coercion: Overstatement or understatement?, Archives of Sexual Behavior 29 (2000), pp. 323-334.

Barnett et al., 1997 O.W. Barnett, C.L. Miller-Perrin and R.D. Perrin, Courtship violence and date rape, Family violence across the life span, Sage Publications, Thousand Oaks, CA (1997), pp. 161-181.

Berkowitz, 2001 A.D. Berkowitz, Critical elements of sexual assault prevention and risk reduction programs for men and women. In: C. Kilmartin, Editor, Sexual assault in context: Teaching college men about gender, Learning Publications, Holmes Beach (2001).

Bernat et AL., 1998 J. Bernat, K. Calhoun and S. Stolp, Sexually aggressive men's response to a date rape analogue: Alcohol as a disinhibiting cue, Journal of Sex Research 35 (1998) (4), pp. 341-348.

Bernat et AL., 1999 J. Bernat, K. Calhoun and H. Adams, Sexually aggressive and nonaggressive men: Sexual arousal and judgments in response to acquaintance rape and consensual analogues, Journal of Abnormal Psychology 108 (1999) (4), pp. 662-673.

Brownmiller, 1975 S. Brownmiller, Against our will: Men, women, and rape, Simon and Schuster, New York (1975).

Bumby, 1996 K.M. Bumby, Assessing the cognitive distortions of child molesters and rapists: Development and validation of the MOLEST and RAPE scales, Sexual Abuse: A Journal of Research and Treatment 8 (1996) (1), pp. 37-54.

Burt, 1980 M. Burt, Cultural myths and supports for rape, Journal of Personality and Social Psychology 38 (1980) (2), pp. 217-230.

Byers \& Eno, 1991 E. Byers and R. Eno, Predicting men's sexual coercion and aggression from attitudes, dating history, and sexual response, Journal of Psychology and Human Sexuality 4 (1991) (3), pp. 5569.

Calhoun et Al., 1997 K.S. Calhoun, J.A. Bernat, G.A. Clum and C.L. Frame, Sexual coercion and attraction to sexual aggression in a community sample of young men, Journal of Interpersonal Violence 12 (1997) (3), pp. 392-406.

Check et AL., 1985 J.V.P. Check, N.M. Malamuth, B. Elias and S. Barton, On hostile ground, Psychology Today (1985, April), pp. 56-61.

DAvIS, 1980 M.H. Davis, A multidimensional approach to individual differences in empathy, JSAS Catalog of Selected Documents in Psychology 10 (1980), p. 85.

DAvis, 1996 M.H. Davis, Empathy: A social psychological approach, Westview, Boulder, CO (1996).

DAvis \& LidDelL, 2002 T.L. Davis and D.L. Liddell, Getting inside the house: The effectiveness of a rape prevention program for college fraternity men, Journal of College Student Development 43 (2002) (1), pp. 35-50.

Dhawan \& Marshall, 1996 S. Dhawan and W.L. Marshall, Sexual abuse histories of offenders, Sexual Abuse: A Journal of Research and Treatment 8 (1996) (1), pp. 7-15.

Fernandez \& Marshall, 2003 Y. Fernandez and W.L. Marshall, Victim empathy, social self-esteem, and psychopathy in rapists, Sexual Abuse: A Journal of Research and Treatment 15 (2003) (1), pp. 11-26.

Forbes \& AdAms-Curtis, 2001 G.B. Forbes and L. Adams-Curtis, Experiences with sexual coercion in college males and females: Role of family conflict, sexist attitudes, acceptance of rape myths, self-esteem, and the Big-Five personality factors, Journal of Interpersonal Violence 16 (2001) (9), pp. 865889.

Forman \& WADSWORTH, 1985 B.D. Forman and C.J. Wadsworth, Rape-related services in federally funded community mental health centers, Journal of Community Psychology 13 (1985) (4), pp. 402-408.

Gidycz et AL., 2001 C.A. Gidycz, M.J. Layman, C.L. Rich, M. Crothers, J. Gylys, A.I. Matorin and C.D. Jacobs, An evaluation of an acquaintance rape prevention program: Impact on attitudes, sexual aggression, and sexual victimization, Journal of Interpersonal Violence 16 (2001) (11), pp. 1120-1138.

GiLbert, 1993 N. Gilbert, The wrong response to rape, The Wall Street Journal (1993, June 29), p. A18.

Groth, 1979 A.N. Groth, Men who rape: The psychology of the offender, Plenum, New York (1979).

HARE, 1991 R. Hare, The hare psychopathy checklist—revised, Multi-Health Systems, Toronto (1991).

HARE, 1998 R. Hare, Psychopaths and their nature: Implications for the mental health and criminal justice systems. In: T. Millon, E. Simonsen, M. Birket-Smith and R.D. Davis, Editors, Psychopathy: Antisocial, criminal and violent behavior, Guilford Press, New York (1998).

Harney \& Muehlenhard, 1991 P. Harney and C.L. Muehlenhard, Rape. In: E. Grauerholz and M.A. Koralewski, Editors, Sexual coercion: A sourcebook on its nature, causes, and prevention, Lexington Books, Massachusetts (1991), pp. 3-16. 
Hersh \& Gray-Little, 1998 K. Hersh and B. Gray-Little, Psychopathic traits and attitudes associated with self-reported sexual aggression in college men, Journal of Interpersonal Violence 13 (1998) (4), pp. $456-471$.

Hunter et AL., 2003 J.A. Hunter, A.J. Figueredo, N.M. Malamuth and J.V. Becker, Juvenile sex offenders: Toward the development of a typology, Sexual Abuse: A Journal of Research and Treatment $\mathbf{1 5}$ (2003) (1), pp. 27-48.

Knight ET AL., 1989 R.A. Knight, D.L. Carter and R.A. Prentky, A system for the classification of child molesters: Reliability and classification, Journal of Interpersonal Violence 4 (1989) (1), pp. 3-23.

Knight \& Prentky, 1990 R.A. Knight and R.A. Prentky, Classifying sexual offenders: The development and corroboration of taxonomic models. In: W.L. Marshall, D.R. Laws and H.E. Barbaree, Editors, Handbook of sexual assault: Issues, theories, and treatment of the offender vol. 27, Plenum, New York (1990), p. 405.

Koss, 1992A M.P. Koss, Defending date rape, Journal of Interpersonal Violence 7 (1992) (1), pp. 122-126.

Koss, 1992B M.P. Koss, The underdetection of rape: Methodological choices influence incidence estimates, Journal of Social Issues 48 (1992) (1), pp. 61-75.

Koss, 1993 M.P. Koss, Detecting the scope of rape: A review of prevalence research methods, Journal of Interpersonal Violence 8 (1993) (2), pp. 198-222.

Koss, 2000 M.P. Koss, Evolutionary models of why men rape, Trauma, Violence, and Abuse 1 (2000) (2), pp. 182-190.

Koss \& Cook, 1998 M.P. Koss and S.L. Cook, Facing the facts: Date and acquaintance rape are significant problems for women. In: R.K. Bergen, Editor, Issues in intimate violence, Sage Publications, Thousand Oaks, CA (1998), pp. 147-156.

Koss \& Dinero, 1988 M.P. Koss and T.E. Dinero, Predictors of sexual aggression among a national sample of male college students. In: Robert A. Prentky and Vernon L. Quinsey, Editors, Human sexual aggression: Current perspectives vol. 528, Annals of the New York Academy of Sciences, New York, NY (1988), pp. 133-147.

Koss \& Gidycz, 1985 M.P. Koss and C.A. Gidycz, Sexual experiences survey: Reliability and validity, Journal of Consulting and Clinical Psychology 53 (1985) (3), pp. 422-423.

Koss ET AL., 1987 M.P. Koss, A. Gidycz and N. Wisniewski, The scope of rape: Incidence and prevalence of sexual aggression and victimization in a national sample of higher education students, Journal of Consulting and Clinical Psychology 55 (1987) (2), pp. 162-170.

Koss et AL., 1985 M.P. Koss, K.E. Leonard, D.A. Beezley and C.J. Oros, Nonstranger sexual aggression: A discriminant analysis of the psychological characteristics of undetected offenders, Sex Roles 12 (1985), pp. 981-992.

Koss \& Oros, 1982 M. Koss and C.J. Oros, Sexual experiences survey: A research instrument investigating sexual aggression and victimization, Journal of Consulting and Clinical Psychology 50 (1982) (3), pp. 455-457.

Kosson \& Kelly, 1997 D.S. Kosson and J.C. Kelly, Psychopathy-related traits predict self-reported sexual aggression among college men, Journal of Interpersonal Violence 12 (1997) (2), pp. 241-258.

LindSey et AL., 2001 R.E. Lindsey, A.F. Carlozzi and G.T. Eells, Differences in the dispositional empathy of juvenile sex offenders, non-sex-offending delinquent juveniles, and nondelinquent juveniles, Journal of Interpersonal Violence 16 (2001) (6), pp. 510-522.

LISAK, 1994 D. Lisak, Subjective assessment of relationship's with parents by sexually aggressive and nonaggressive men, Journal of Interpersonal Violence 9 (1994) (3), pp. 399-411.

LISAK \& Ivan, 1995 D. Lisak and C. Ivan, Deficits in intimacy and empathy in sexually aggressive men, Journal of Interpersonal Violence 10 (1995) (3), pp. 296-308.

LisaK \& Rотн, 1988 D. Lisak and S. Roth, Motivational factors in nonincarcerated sexually aggressive men, Journal of Personality and Social Psychology 55 (1988) (5), pp. 795-802.

Malamuth, 1988 N.M. Malamuth, A multidimensional approach to sexual aggression: Combining measures of past behavior and present likelihood. In: Robert A. Prentky and Vernon L. Quinsey, Editors, Human sexual aggression: Current perspectives vol. 528, Annals of the New York Academy of Sciences, New York, NY (1988), pp. 123-132.

Malamuth, 1981 N.M. Malamuth, Rape proclivity among males, Journal of Social Issues 37 (1981) (4), pp. $138-157$.

Malamuth et aL., 1986 N.M. Malamuth, J.V.P. Check and J. Briere, Sexual arousal in response to aggression: Ideological, aggressive, and sexual correlates, Journal of Personality and Social Psychology 50 (1986) (2), pp. 330-340. 
Malamuth et AL., 1993 N.M. Malamuth, C.L. Heavey and D. Linz, Predicting men's antisocial behavior against women: The interaction model of sexual aggression. In: G.N. Hall, J. Hirschman, J. Graham and M. Zaragoza, Editors, Sexual Aggression: Issues in etiology, assessment and treatment, Hemisphere, Washington, D.C. (1993), pp. 63-97.

Malamuth et AL., 1991 N.M. Malamuth, R.J. Sockloskie, M.P. Koss and J.S. Tanaka, Characteristics of aggressors against women: Testing a model using a national sample of college students, Journal of Consulting and Clinical Psychology 59 (1991) (5), pp. 670-681.

Marshall et Al., 1995 W.L. Marshall, S.M. Hudson, R. Jones and Y.M. Fernandez, Empathy in sex offenders, Clinical Psychology Review 15 (1995), pp. 99-113.

Marshall \& Maric, 1996 W.L. Marshall and A. Maric, Cognitive and emotional components of generalized empathy deficits in child molesters, Journal of Child Sexual Abuse 5 (1996), pp. 101-110.

Mosher \& Anderson, 1986 D.L. Mosher and R.D. Anderson, Macho personality, sexual aggression, and reactions to guided imagery of realistic rape, Journal of Research in Personality 20 (1986), pp. 77-94.

Muehlenhard \& Falcon, 1990 C. Muehlenhard and P. Falcon, Men's heterosocial skill and attitudes toward women as predictors of verbal sexual coercion and forceful rape, Sex Roles 23 (1990) (5/6), pp. 241259.

Nagayama Hall \& Hirshman, 1991 G.C. Nagayama Hall and R. Hirshman, Toward a theory of sexual aggression: A quadripartite model, Journal of Consulting and Clinical Psychology 59 (1991) (5), pp. 662-669.

RAPAPORT \& Burkhart, 1984 K. Rapaport and B.R. Burkhart, Personality and attitudinal characteristics of sexually coercive college males, Journal of Abnormal Psychology 93 (1984) (2), pp. 216-221.

RoIPHE, 1993 K. Roiphe, The morning after: Sex, fear, and feminism on campus, Brown Little, Boston (1993).

Schewe \& O'Donohue, 1996 P.A. Schewe and W.T. O'Donohue, Rape prevention with high-risk males: Short-term outcome of two interventions, Archives of Sexual Behavior 25 (1996) (5), pp. 455-471.

Senn et Al., 2000 C. Senn, S. Desmarasis, N. Verberg and E. Wood, Predicting coercive sexual behavior across the life span in a random sample of Canadian men, Journal of Social and Personal Relationships 17 (2000) (1), pp. 95-113.

Simons et AL., 2002 D. Simons, S.K. Wurtele and P. Heil, Childhood victimization and lack of empathy as predictors of sexual offending against women and children, Journal of Interpersonal Violence 17 (2002) (12), pp. 1291-1307.

Smallbone et AL., 2003 S.W. Smallbone, J. Wheaton and D. Hourigan, Trait empathy and criminal versatility in sexual offenders, Sexual Abuse: A Journal of Research and Treatment 15 (2003) (1), pp. 49-60.

SPEnCE Et AL., 1973 J.T. Spence, R. Helmreich and J.A. Stapp, A short version of the Attitudes Towards Women Scale, Bulletin of the Psychonomic Society 2 (1973), pp. 219-220.

Strauss, 1979 M.A. Strauss, Measuring intrafamily conflict and violence: The Conflict Tactics (CT) Scales, Journal of Marriage and Family 41 (1979), pp. 75-88.

Testa \& Dermen, 1999 M. Testa and K.H. Dermen, The differential correlates of sexual coercion and rape, Journal of Interpersonal Violence 14 (1999) (5), pp. 548-561.

Tyler ET AL., 1998 K.A. Tyler, D.R. Hoyt and L.B. Whitbeck, Coercive sexual strategies, Violence and Victims 13 (1998) (1), pp. 47-61.

WIDOM, 1989 C.S. Widom, Child abuse, neglect and adult behavior: Research design and findings on criminality, violence, and child abuse, American Journal of Orthopsychiatry 58 (1989), pp. 260-270.

WIDOM, 2000 C.S. Widom, Motivation and mechanisms in the "Cycle of Violence". In: D.J. Hansen, Editor, Motivation and child maltreatment vol. 46, University of Nebraska Press, Lincoln (2000).

Worling, 2001 J.A. Worling, Personality-based typology of adolescent male sexual offenders: Differences in recidivism rates, victim-selection characteristics, and personal victimization histories, Sexual Abuse: A Journal of Research and Treatment 13 (2001) (3), pp. 149-166.

Zweig ET AL., 1997 J.M. Zweig, B. Barber and J. Eccles, Sexual coercion and well-being in adulthood: Comparisons by gender and college status, Journal of Interpersonal Violence 12 (1997) (2), pp. 291-308. 